\title{
AUTOPSY RESULTS OF FAILED LITHIUM COLLECTION LENSES AT THE FNAL ANTIPROTON SOURCE ${ }^{*}$
}

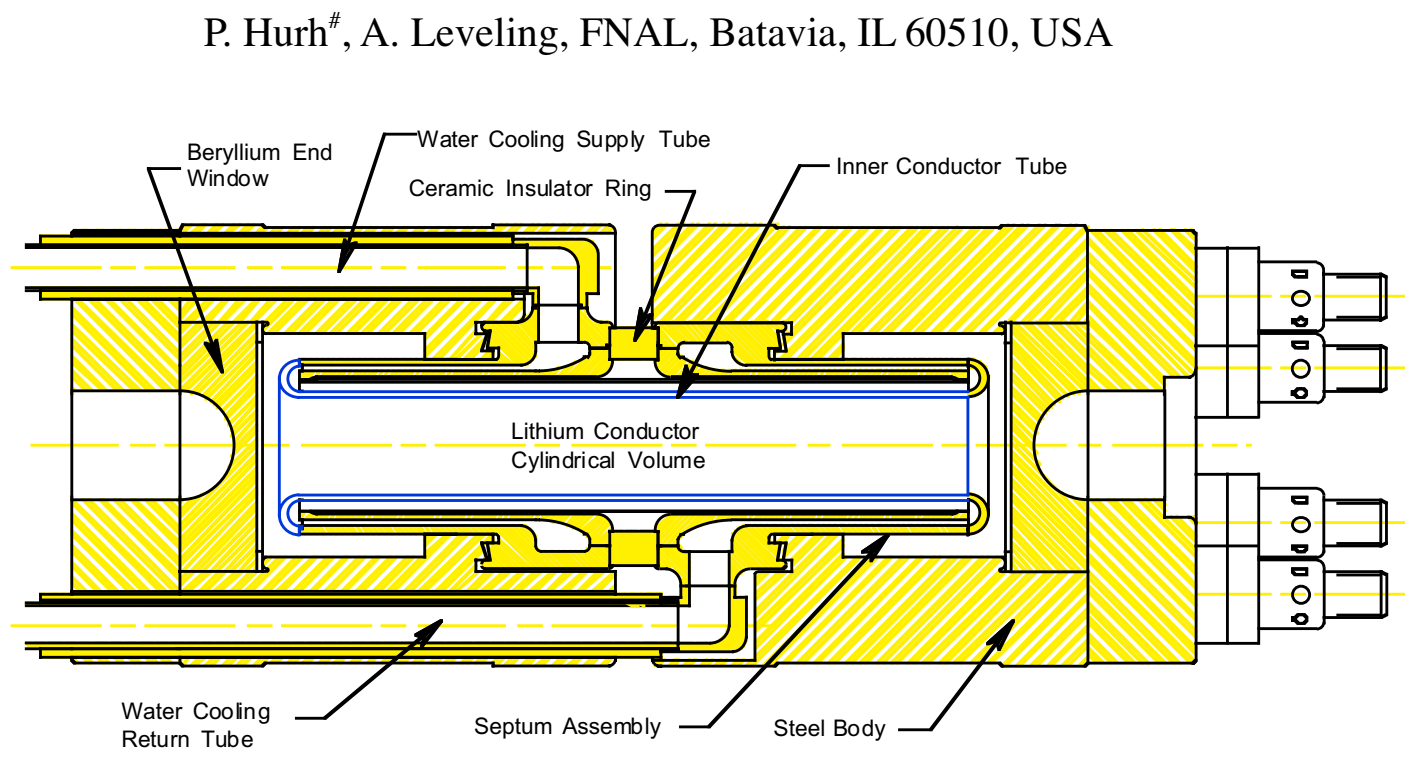

Figure 1: Cross-section diagram of Collection Lens Device. Septum conductor tube is shown in blue.

\section{Abstract}

A lithium lens focusing device is used at the FNAL Antiproton Source to collect antiprotons immediately downstream of the production target. Recently developed methods of removing lithium from old collection lens devices have enabled the dissection and autopsy of several failed lenses. Examination reveals longitudinal fatigue cracks in the titanium alloy $(6 \mathrm{Al}-4 \mathrm{~V})$ cooling jackets. A finite element analysis to estimate stress intensity factors expected in the cooling jackets is presented and compared to the crack propagation and fracture toughness thresholds for Ti $6 \mathrm{Al}-4 \mathrm{~V}$. Results presented indicate that crack initiation and propagation at the currently estimated service loads are unlikely without additional material degradation mechanisms at work.

\section{INTRODUCTION}

Failures of Collection Lens devices at the AP-0 P-bar Target Hall in the past have generally been left uninspected due to the level of residual radioactivity and the semi-hazardous nature of lithium metal. Recently however the passage of time and development of methods to safely remove lithium from a Lens assembly have allowed failure investigation [1]. Five Lens assemblies have been so 'unfilled' and unassembled. However only two assemblies (numbered 20 and 21) have been examined in detail. Both Lenses were constructed in 1993 and failed in service (in 1995) after only a few hundred thousand pulses each, both much earlier than what would be expected from previous Lenses (lifetimes of several

*Work supported by the US Department of Energy under contract No. DE-AC02-76CH03000.

"hurh@fnal.gov million pulses). Both Lenses appeared to fail due to breaches in the titanium alloy (Ti 6Al-4V) cooling jacket (historically called the septum).

The cross-section of the Lens assembly and septum is shown in Figure 1. The septum of a Collection Lens serves two functions. Firstly, it contains the structurally soft lithium in the cylindrical shape of the central conductor. Secondly, it cools the central lithium conductor by removing heat deposited by the current pulse and the beam pulse from the conductor into a Low Conductivity Water (LCW) system.

The most highly stressed part of the septum is the conductor tube. Stresses arise from several loading sources such as thermal expansion from the current pulse (nearly $500 \mathrm{kA}$ at operating gradient) and the beam pulse, magnetic forces from the current pulse, and structural loading from clamping bolts and lithium filling pre-load. This tube directly contacts the lithium central conductor cylinder on its inner radius surface $(1 \mathrm{~cm}$ radius) and directly contacts longitudinally flowing LCW on its outer radius surface. The conductor tube wall thickness is 1 $\mathrm{mm}$. It is this conductor tube of each Lens that was the subject of this investigation.

\section{FAILURE DESCRIPTION}

Conductor tubes of both Lenses appeared to fail due to a single longitudinal crack through the wall thickness of each tube. This breaching of the septum in each case allowed LCW to come in contact with the lithium. Since lithium and water react to form lithium hydroxide and hydrogen gas exothermically, considerable damage to the conductor tube could occur (especially during subsequent current pulses). This damage could obscure features of the initial tube failure. 


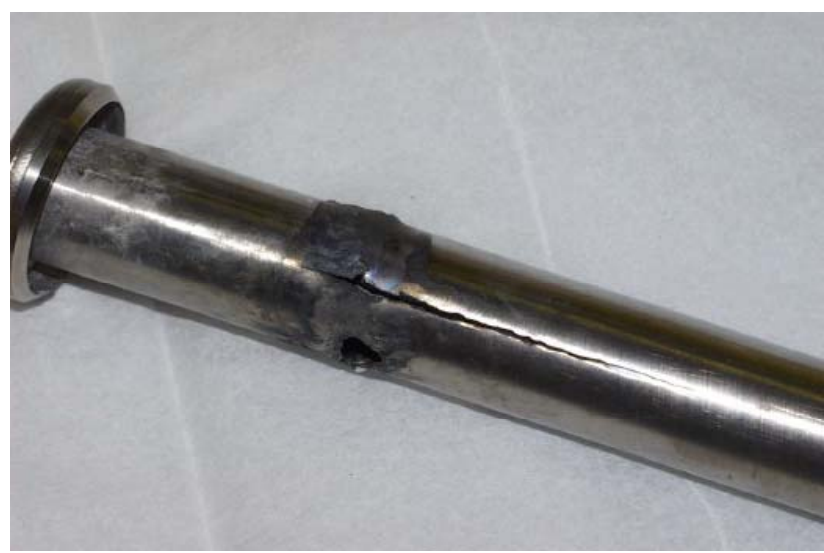

Fig. 2: Lens 21 septum conductor tube showing longitudinal crack and melted through area.

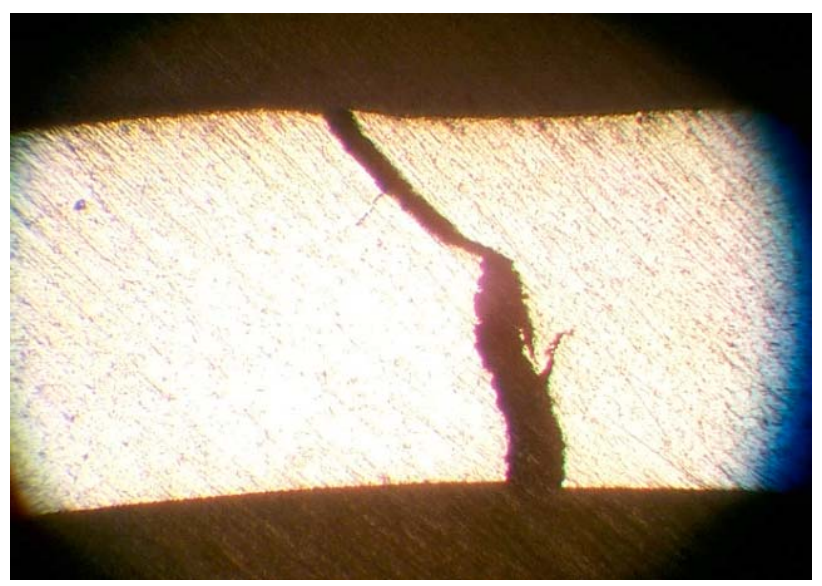

Fig. 3: Lens 20 conductor tube crack profile. ID surface at bottom of picture. Tube wall thickness: $1 \mathrm{~mm}$.

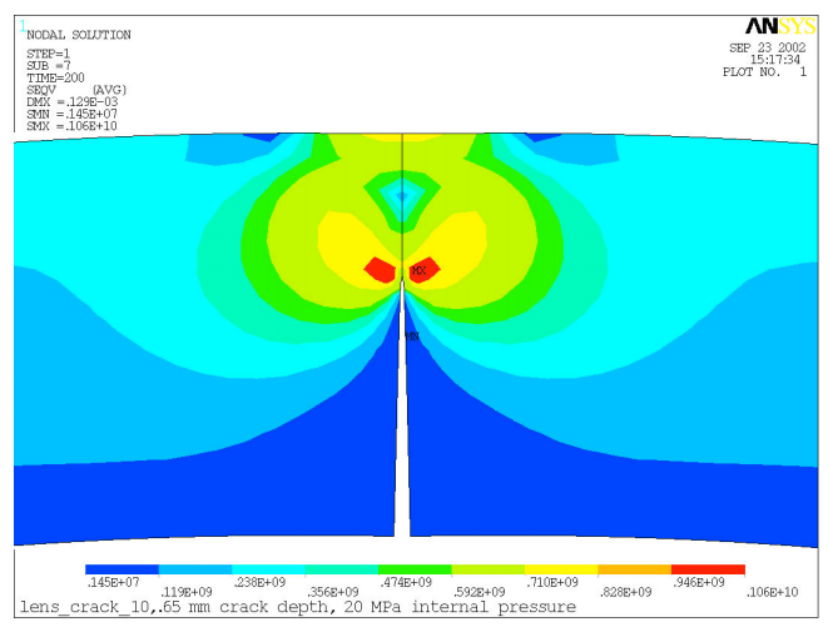

Fig. 4: Von Mises stress equivalent in crack area of ANSYS ${ }^{\circledR}$ model.

In addition, the exit of lithium from the cylindrical conductor volume could create voids which may promote localized areas of extreme heating or even arcing. Finally, both Lenses were stored for long periods of time before dissection. Lithium hydroxide solution, present in the
Lenses over the 6 year period between failure and unfilling, may have corroded or otherwise affected septum surfaces.

\section{Macroscopic Features}

Figure 2 shows the conductor tube from Lens 21 with the longitudinal crack which is presumed to have occurred first. In addition Figure 2 shows a badly burned and, in places, melted region at one end of the longitudinal crack. The region is continuous around the circumference of the tube. The tube wall is actually bulged out in this damaged region presumably from internal pressure or a small explosion. The titanium alloy appears to have local areas of melting ( $\mathrm{Ti} 6 \mathrm{Al}-4 \mathrm{~V}$ melting point is $1650{ }^{\circ} \mathrm{C}$ ). The conductor tube from Lens 20 appears very similar to that of Lens 21 (including the longitudinal crack) except for the absence of the bulged out region.

\section{Crack Cross-sections}

The conductor tubes of both Lenses were prepared into cross-section samples. Figure 3 shows a typical profile of the through wall crack. Most of the profiles studied show two distinct crack propagation regimes, a region of seemingly brittle cyclic crack propagation near the ID surface and a region of ductile fracture near the OD surface. This indicates that the crack originated on the ID surface and progressed cyclically outward. Once the crack had progressed far enough to weaken the wall sufficiently, the crack progressed rapidly in a ductile fashion to the OD surface. In addition in many of the profiles, some reduction of area (or necking) can be observed at the OD surface indicating considerable plastic deformation before complete failure.

Estimations of the loading just prior to the final ductile failure can be made by observing the remaining wall thickness just before final rupture. Using a 2-D ANSYS ${ }^{\circledR}$ [2] finite element model and a crack depth of $0.65 \mathrm{~mm}$, various load magnitudes were investigated. Figure 4 shows the equivalent stress in the crack area of the model under $20 \mathrm{MPa}$ of internal pressure (equivalent to $200 \mathrm{MPa}$ of hoop stress). The stress pattern and deformation shape are in agreement with the photographed cross-sections. Using an ANSYS ${ }^{\circledR}$ routine, KCALC, the stress intensity factor for this geometry and loading was calculated to be 64.5 MPa- $\mathrm{m}^{-1 / 2}$. This can be compared to the fracture toughness of mill annealed titanium alloy $(6 \mathrm{Al}-4 \mathrm{~V})$ of 64.9 $\mathrm{MPa}^{-1 / 2} \mathrm{~m}^{2}[3]$. For comparison, hoop stress in the conductor tube pulsed at normal operating gradient (745 $\mathrm{T} / \mathrm{m}$ ) predicted by a full Lens FEA [4] is $343 \mathrm{MPa}$.

Although loads predicted by FEA are large enough to agree with observations of the final ductile failure, they are not high enough to explain the initial, brittle crack propagation. The threshold stress intensity factor for $\mathrm{Ti}$ $6 \mathrm{Al}-4 \mathrm{~V}$ below which fatigue crack propagation does not occur is $7 \mathrm{MPa}-\mathrm{m}^{-1 / 2}$. Using a similar FEA crack model, it is predicted that an initial crack would have to be 0.15 to $0.25 \mathrm{~mm}$ deep before propagating at a rate high enough to fail in the 10E6 cycles range. 


\section{Micro-cracks}

The cross-section samples were examined under high magnification. Micro-cracks on the order of 10 to 20 microns deep can be seen in Figure 5. The cracks appear to be inter-granular and fairly blunted. In addition, there are locations near the opening of the large, through crack that appear pitted with rice grain shaped voids. All of the micro-cracks are on the ID surfaces of the samples.

The cause of these micro-cracks is not readily apparent, although the role they play in initiating fatigue failure may be critical. Their appearance may indicate some sort of corrosive or embrittlement mechanism, however drawing conclusions from such minute indications is difficult. In fact the micro-cracks may have been caused by chemical reaction and/or electrical arcing after the failure of the septa.

\section{Fracture Surfaces}

The fracture surfaces of Lens 20 were examined with a SEM. Figure 6 shows a portion of surface in the brittle fracture zone. Note the extremely stratified appearance and pervasive micro-cracking. Figure 7 shows a portion of the surface in the ductile fracture zone. Note that the characteristic ductile dimples are disrupted with a maze of micro-cracks. These surfaces appear to be abraded or corroded after the original failure, possibly by pulsing, arcing, or chemical reaction. Future studies are planned to explain these curious features.

\section{CONCLUSION}

The examinations of failed Collection Lenses 20 and 21 have revealed that the Lenses' septa failed due to fatigue failure. However, fracture features indicate that loads at final failure were not great enough to initiate and propagate small cracks from the ID surface. Thus the loading conditions must have been much more severe earlier in service and/or the fatigue was assisted by degradation of the structural integrity of the Ti $6 \mathrm{Al}-4 \mathrm{~V}$ septa material (such as hydrogen embrittlement, stress

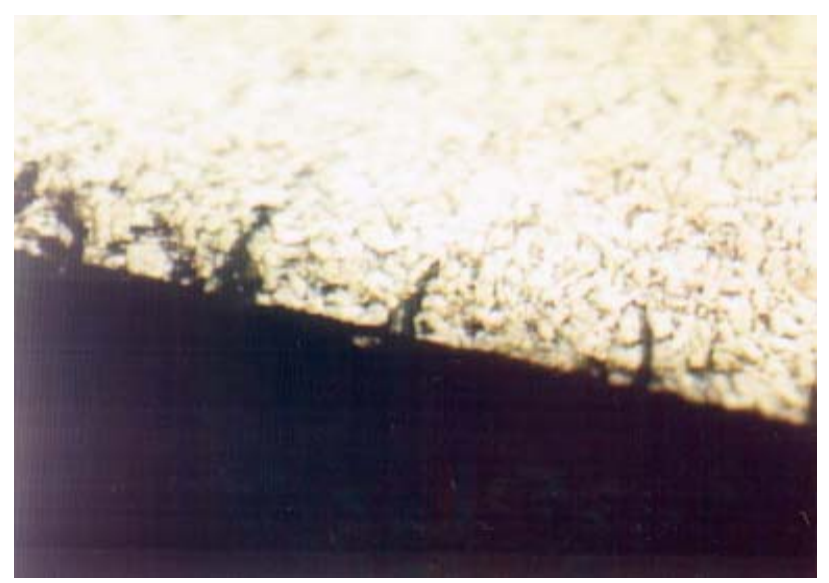

Fig. 5: Lens 21 conductor tube crack profile. Shows micro-cracking on ID surface. 1000x. corrosion cracking, or liquid metal embrittlement). In addition, small micro-cracks were found on the ID surface of the septa conductor tubes which support the latter possibility. Autopsies of this type will be conducted on several other failed lenses and should include fracture toughness testing to identify material degradation. These topics are discussed in greater detail in a Fermilab MSD Note [5].

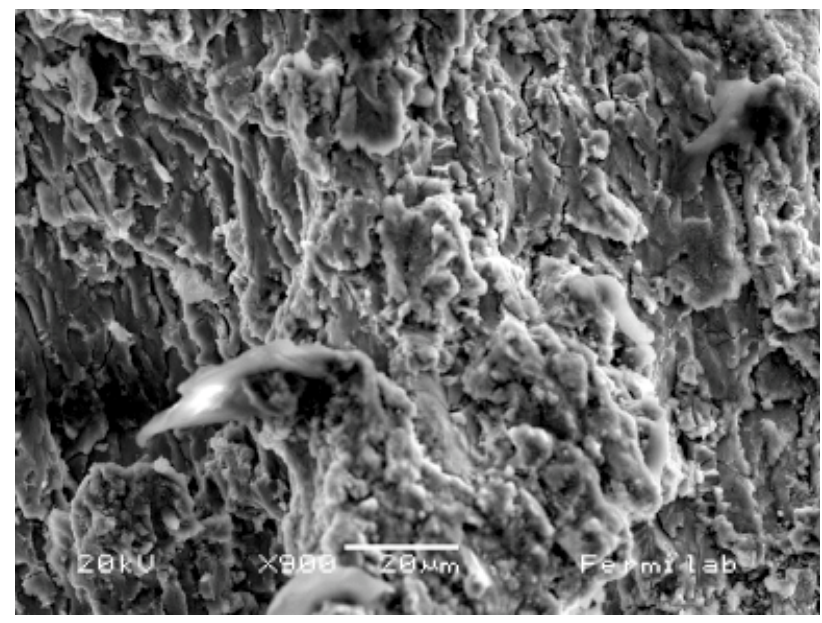

Fig. 6: Lens 20 conductor tube brittle fracture surface.

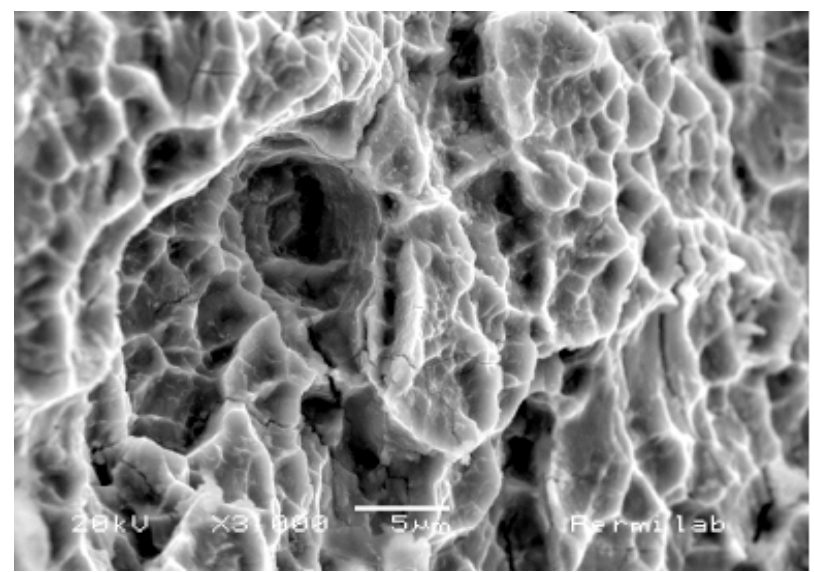

Fig. 7: Lens 20 conductor tube ductile fracture surface.

\section{REFERENCES}

[1] A. Leveling, Fermilab P-bar Note \#664 (2001).

[2] ANSYS $®$ is a registered trademark of SAS IP Inc.

[3] Materials Properties Handbook: Titanium Alloys, edited by R. Boyer, G. Welsch, E.W. Collings, ASM International, Materials Park, p. 582 (1994).

[4] P. Hurh \& S. Tariq, "Comprehensive ElectroMagnetic, Thermal, and Structural Finite Element Analysis of the Lithium Collection Lens at the FNAL Antiproton Source", ROPB011,PAC 2003, Portland (2003).

[5] P. Hurh, "Examination Results of Failed Collection Lens Septa 20 and 21", Fermilab MSDNote \#MSDNME-000022 (2002). 